\title{
Plantaciones forestales versus el bosque nativo
}

\author{
Roberto Cornejo Espósito \\ Presidente Nacional Colegio Ingenieros Forestales, San Isidro 22, oficina 503, Santiago de \\ Chile, email: robertocornejoe@gmail.com
}

En el último tiempo se ha criticado fuertemente por parte de sectores ambientalistas a las plantaciones forestales Pinus insignis D. Don y el Eucaliptus globulus Labill, afirmando lo perjudiciales y dañinas que son para el medio ambiente y su impacto negativo en la mantención del bosque nativo (INFOR, 2014). Las principales críticas apuntan a que se está sustituyendo bosque nativo por plantaciones, que los monocultivos acidifican el suelo, no permitiendo posteriormente otros cultivos "más nobles", que estas especies secan los cauces de agua (Donoso \& Otero, 2005) La realidad indica que lo señalado no tiene bases científicas. En relación a la amenaza de los monocultivos al bosque nativo, no existe una relación entre estas dos formaciones vegetales. El bosque nativo ha visto aumentada su superficie en Chile, En efecto, hay 170.000 ha más en la actualidad que en el año 1997 (Lara et al., 2012).

Por otra parte, muchos suelos que fueron en el pasado plantados con. P. insignis, se han utilizado en otros usos y no se ha registrado problemas de productividad. El cambio climático como consecuencia del cambio de usos de suelos es responsable de las menores precipitaciones y no la presencia de bosques, sean estos naturales o plantados (Lara et al., 2012). Los suelos disponibles para nuevas plantaciones están gravemente erosionados precisamente por la falta de una cubierta vegetal. Sólo reforestar con bosques nativos en suelos forestales degradados, permitirá recuperar paulatinamente dichos suelos e incorporar riqueza donde hoy hay pobreza (INFOR, 2014).

Hoy tenemos en el país una superficie cerca de 2.000.000 de hectáreas desprovistas de vegetación, suelos desnudos que se encuentran muy erosionados. La mayoría de la propiedad de esos terrenos está en manos de pequeños y medianos propietarios. Una de las mejores alternativas es forestar esos terrenos desarbolados, de manera de controlar la erosión y a la vez entregar una solución social, económica y ambiental a sus propietarios y entregar una posibilidad de disponibilidad de madera a las pequeñas empresas forestales (INFOR, 2014). 
A pesar de los buenos deseos de quienes proponen especies nativas para esta labor, actualmente es difícil y a veces imposible utilizar las especies nativas originarias. Esos terrenos ya no tienen las condiciones para su adecuado desarrollo, de manera que se debe enfrentar el desafío de forestar con especies menos exigentes, y que son precisamente las mismas que sirven para conformar plantaciones de rápido crecimiento. Estas especies pueden responder a las necesidades de los pequeños propietarios, entregando una solución de desarrollo, debido que en la actualidad esos terrenos tienen muy poco uso y bajísima o nula productividad (INFOR, 2014). Hay que tener presente que tenemos más de 13,6 millones de hectáreas de bosque nativo y sólo 2,6 millones de hectáreas de plantaciones forestales de rápido crecimiento. Estas últimas, pese a representar menos del $20 \%$ de la superficie de las primeras, han logrado constituir el segundo rubro de importancia de la economía de Chile las que se encuentran en las regiones del Biobio, Araucanía y Los Ríos (INFOR, 2014).

Desde el año 2013 caducó el DL.701 de Fomento Forestal, instrumento que ha sido fundamental para el desarrollo forestal del país. Produciendo una baja en las plantaciones de 70.000 hectáreas anuales a 6.300 hectáreas en 2013 y el año 2014 a 4.419 hectáreas (CONAF, los documentos de plantaciones forestales del 2013 y del año 2014). Sin embargo, las forestaciones están siendo cuestionadas en que sólo se acepta el fomento para el bosque nativo, lo que estaría impidiendo un adecuado desarrollo de los pequeños propietarios de suelos sin vegetación y muy degradados.

\section{Referencias}

Donoso, P.J. \& L.A. Otero, (2005). Hacia una definición de país forestal: ¿Dónde se sitúa Chile?. Bosque 26(3): 5-18.

Instituto Forestal- INFOR, 2014. Anuario Forestal. Boletín Estadístico 144. Santiago de Chile. $166 \mathrm{p}$.

Lara, A., M.E. Solari, M.R. Prieto \& M.P. Peña (2012). Reconstrucción de la cobertura de la vegetación y uso de suelo hacia 1550 y sus cambios a 2007 en la ecorregión de los bosques

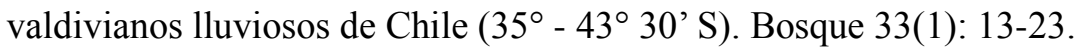

CONAF. Plantaciones forestales las ediciones del año 2013 y 2014 